\title{
A Bi-Spectral Method for Cloud Parameter Determination
}

\author{
By
}

David W. Reynolds and Thomas H. Vonder Haar

\author{
Department of Atmospheric Science \\ Colorado State University \\ Fort Collins, Colorado
}

Support provided by the Global Atmospheric Research Program, NSF, and the GATE Project Office, National Oceanic and Atmospheric Administration. Support was also provided by the Meteorological Technical Area of the US Army Electronics Command, White Sands Missile Range, New Mexico.

January 1976

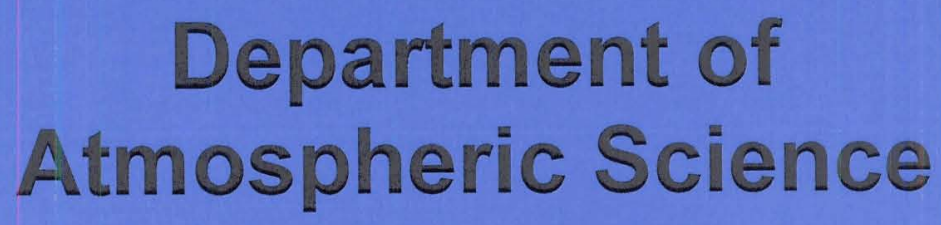

Paper No. 239 


\title{
A BI-SPECTRAL METHOD FOR \\ CLOUD PARAMETER DETERMINATION
}

\author{
by \\ David W. Reynolds \\ and \\ Thomas H. Vonder Haar
}

Support provided by the Global Atmospheric Research Program, NSF, and the GATE Project Office, National Oceanic and Atmospheric Administration. Support was also provided by the Meteorological Technical Area of the U.S. Army Electronics Command, White Sands Missile Range, New Mexico.

\author{
Department of Atmospheric Science \\ Colorado State University \\ Fort Collins, Colorado
}

January 1976

Atmospheric Science Paper No. 239 


\subsection{INTRODUCTION}

With the launch of the TIROS (1961-1965) and ESSA (1966-1969) series of satellites, interest arose in trying to determine cloud amount and cloud type (low, middle, high) from satellite data in an objective manner (Conover, 1962, 1963; Leese, 1964; Mi1ler et a1., 1970). After the launch of meteorological satellites such as Nimbus 2 and 3 carrying reliable infrared radiometers, multi-spectral techniques were developed to match data from different satellite sensors viewing the same cloud fields (Vonder Haar, 1970; Shenk and Holub, 1972). Beginning with ITOS-1 (1970) simultaneous high resolution visible and infrared data points from satellites were matched precisely in both space and time. Study of these combined data sets showed them to contain much more information than when both data channels were considered separately (Booth, 1973).

Figure 1 is an example of the simultaneous visible and IR data received from the scanning radiometer (SR) onboard the NOAA-2 spacecraft. As can be seen, the most striking difference between the two pictures is the cloudiness on the visible picture in southeast Colorado which disappears for the most part on the infrared picture of this area. In this case the clouds are bright and warm signifying the presence of low clouds, i.e., stratus. The clouds in the northern portion of Colorado show up bright in the visible and white (cold) in the IR signifying fairly deep, high clouds. The clouds over Washington, Oregon and Northern California appear very thin and gray on the visible image while on the infrared view these clouds cover a much larger area and are white (cold); thus probabiy indicating cirrus.

The bi-spectral technique of the present paper goes a step further than qualitative comparison of these combined data sets by analyzing both the visible and infrared data received at a single measurement point or 


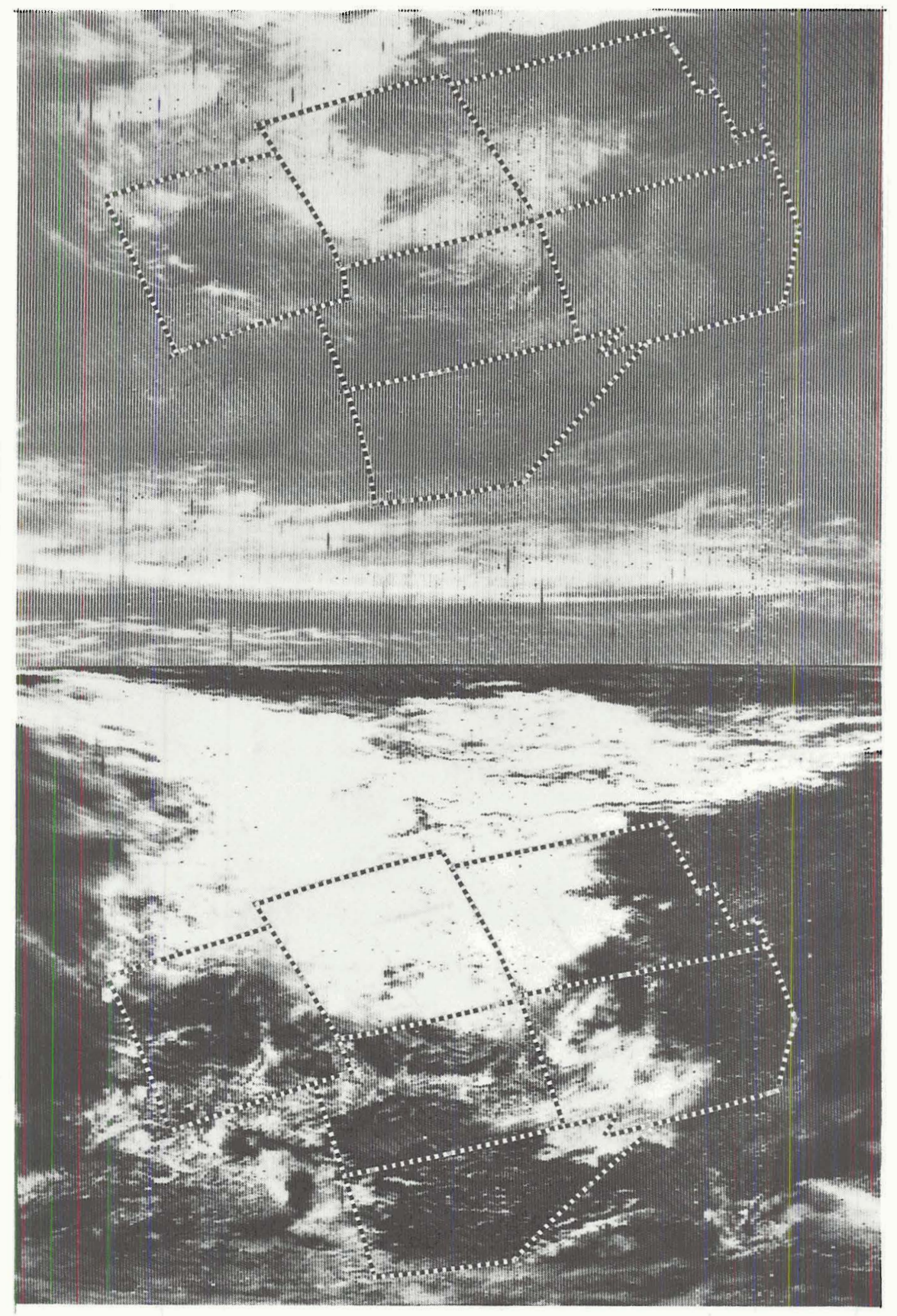

Figure 1. Hard copy print from the visible (left) and IR (right) channel of the Scanning Radiometer onboard NOAA-2 which is received directly at Colorado State University's APT station. 
contiguous array of scan spots in a quantitative manner. From these data we derive the cloud amount $\left(A_{C L D}\right)$ and the cloud top temperature $T_{C L D}=$ $T_{C L D}\left(N_{C L D}\right)$; through an appropriate vertical temperature sounding we derive cloud height. The technique is also designed to approach the problem of determining cloud amounts and heights for cloud sizes below the size of the sensors geometric field of view. The present paper will present the theory for the bi-spectral technique as well as the assumptions that are made. An uncertainty analysis is used to show the required measurement accuracy needed for the technique to be successful. Verification of this technique is shown by using data obtained from the NOAA polar orbiting satellites together with concurrect cloud estimates from the ground. The bi-spectral techniques should prove valuable in the analysis of SMS/GOES data as well as for several other satellite data sets which have simultaneous visible and infrared capabilities.

\subsection{GENERAL. BI-SPECTRAL METHOD \\ Consider a single measurement spot:}

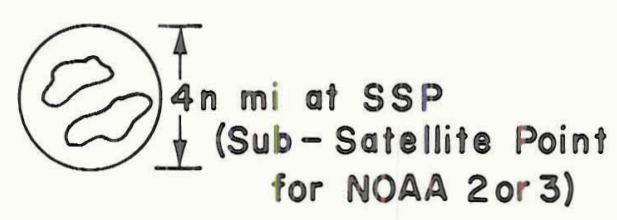

or a measurement array:

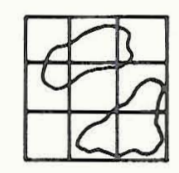

POP NOAA 2OP 3)

each containing a fraction of their total area covered with clouds ( $A_{C L D}$ ' in tenths) and the remaining fraction cloudfree $\left(A_{C L R}\right)$. At each scan spot and for each finite array we assume the availability of two spectral radiance measurements from a satellite, $M_{S}$ (i.e. $0.5<\lambda<0.8 \mu \mathrm{m}$ ) and $M_{L}$ (i.e., $10<\lambda<11 \mu \mathrm{m})$. The magnitudes of the measured radiances may be assumed to arise from:

$$
M_{S}=\left(A_{C L R}{ }^{a} C L R{ }_{S}+A_{C L D}{ }^{a_{C L D}}{ }_{S}\right)
$$


with: $\quad a=$ albedo of the surface (cloud, land or ocean)

$$
\begin{aligned}
H_{S}= & \text { the solar irradiance }(i . \text { e. }, 0.5<\lambda<0.8 \mu \mathrm{m}) \\
& \text { reaching the surface; } H_{S}=N^{\prime} \Omega_{S U N} \\
N^{\prime}= & \text { solar constant for the satellite }
\end{aligned}
$$

and assuming:

a) that bi-directional reflectance effects can be accounted for within "a"; for diffuse case, $a=\pi p$

b) that $H_{S}$ is the same at all levels in the atmosphere,

and a.1so

$$
M_{L}=A_{C L R} N_{C L R}+A_{C L D} N_{C L D}
$$

with $N_{C L R}$ and $N_{C L D}$ the spectral infrared ( $i . e ., 10<\lambda<11 \mu m$ ) radiance arising from the cloudfree and clear regions viewed respectively and assuming:

a) that the infrared emissivity of the (water) clouds and surface is .9.

b) that clouds in view have al1 tops at nearly the same level (i.e., $\pm 500 \mathrm{~m}$ )

Equations (1) and (2) may be joined by the relation implied above:

$$
A_{C L D}+A_{C L R}=1.00
$$

and the set solved for the two desired unknowns:

$$
A_{C L D} \text { and } N_{C L D}
$$

(where $N_{C L D}$ yields $T_{\text {eff }}$ of clouds, from Planck's Law).

provided we assume "a priori" knowledge of:

$$
\begin{aligned}
& { }^{a}{ }_{C L R}=\text { the albedo of the cloudfree region (i.e., } 10 \text { for } \\
& { }^{a}{ }_{C L D}=\text { the albedo of the cloud (i.e., 0.50) }
\end{aligned}
$$

and

$$
\begin{aligned}
{ }^{N} C L R & =\text { the infrared radiance from the cloud-free surface } \\
& \left(i . e ., N_{C L R}=F\left(T_{S}\right)\right)
\end{aligned}
$$


A11 of this "a priori" information can be acquired in practice from the actual array of satellite measurements, using suitable methods such as "minimum albedo" (Vonder Haar et.al., 1973); "clear column radiance" (Smith, 1974), etc. A complete description of these methods is beyond the scope of this paper. However, an uncertainty analysis to test the effect of these assumptions used in the bi-spectral method will be included in the next section.

The solutions for (1), (2) and (3) for cloud amount and cloud radiance are:

$$
A_{C L D}=\frac{M_{S}-\rho_{C L R} H_{S}}{H_{S}\left(\rho_{C L D}{ }^{-\rho} C L R\right.}
$$

and:

$$
N_{C L D}=\frac{M_{L}-N_{C L R}}{A_{C L D}}+N_{C L R}
$$

\subsection{UNCERTAINTY ANALYSIS}

The general approach contains several assumptions. Since there are many methods to infer the required "a priori" data, as well as possibilities for iterative solutions, the practical application of the bi-spectral method to determine cloud parameters to meet the need of air operations, temperature soundings, wind sets from SMS, etc. will depend first of all on uncertainties in the measured radiances $M_{S}$ and $M_{L}$. To test the method we have thus proceeded through the development in reverse order.

Differentiating Equation (4) implicitly:

$$
\left.\Delta A_{C L D}=\frac{\Delta M_{S}}{M_{S}}\left[\frac{M_{S}}{H_{S}\left(\rho_{C L D}{ }^{-\rho} C L R\right.}\right)\right] \quad \text { (continued next page) }
$$




$$
\begin{aligned}
& +\frac{\Delta \rho_{C L R}}{{ }_{C L R}}\left[\frac{\rho_{C L R}\left(M_{S}-H_{S}{ }{ }_{C L D}\right)}{H_{S}\left(\rho_{C L D}{ }^{-} \rho_{C L R}\right)^{2}}\right] \\
& +\frac{\Delta \rho_{C L D}}{\rho_{C L D}}\left[\frac{-\rho_{C L D}\left(M_{S}-\rho_{C L R} H_{S}\right)}{H_{S}\left(\rho_{C L D} \rho_{C L R}\right)^{2}}\right] \\
& +\frac{\Delta H_{S}}{H_{S}}\left[\frac{-M_{S}}{H_{S}\left(\rho_{C L D^{-}} \rho_{C L R}\right)}\right]
\end{aligned}
$$

This shows that the uncertainty in cloud amount $\left(\triangle A_{C L D}\right)$ depends on the magnitude and uncertianty of the incident solar irradiance on the cloud, $\mathrm{H}_{S}$; the reflected solar radiance measured at the satellite, $M_{S}$; and the assumed bi-directional reflectance of the cloud and cloudfree regions, $P_{C L D}$ and ${ }_{C} C L R$, respectively. Note that in most cases $\Delta H_{S}$ and $\Delta \rho_{C L R}$ will be less than $10 \%$ of their magnitudes, $\Delta M_{S}$ can be within $5 \%$ and $\Delta \rho_{C L D}$ can be deduced by direct measurement.

Differentiating (5) we have:

$$
\begin{aligned}
\Delta N_{C L D} & =\frac{\Delta M_{L}}{M_{L}}\left[\frac{M_{L}}{A_{C L D}}\right]+\frac{\Delta A_{C L D}}{A_{C L D}}\left[\frac{N_{C L R}-M_{L}}{A_{C L D}}\right] \\
& +\frac{\Delta N_{C L R}}{N_{C L R}}\left[\frac{N_{C L R}\left(A_{C L D^{-1.0)}}\right.}{A_{C L D}}\right]
\end{aligned}
$$

Equation (6) and (7) were evaluated systematically using these typical mid-latitude values:

$$
\begin{aligned}
H_{S} & =305 \mathrm{~W} \cdot \mathrm{m}^{-2}\left(\text { for } \cos \zeta_{\text {SUN }}=0.82\right) \\
M_{S} & =22 . \mathrm{W} \cdot \mathrm{m}^{-2} \cdot \mathrm{sr}^{-1} \\
M_{L} & =7 . \mathrm{W} \cdot \mathrm{m}^{-2} \cdot \mathrm{sr}^{-1} \\
N_{C L R} & =8.5 \mathrm{~W} \cdot \mathrm{m}^{-2} \cdot \mathrm{sr}^{-1} \cdot \mathrm{um}^{-1} \\
\mathrm{~N}_{C L . D} & =4.0 \mathrm{~W} \cdot \mathrm{m}^{-2} \cdot \mathrm{sr}^{-1} \cdot \mathrm{um}^{-1}
\end{aligned}
$$




$$
\begin{aligned}
& A_{C L R}=0.50 \\
& { }_{C L D}=0.50 \\
& { }^{a_{C L R}}=0.12 \\
& { }^{a_{C L D}}=0.50
\end{aligned}
$$

(the $N_{C L R}$ and $N_{C L D}$ radiances correspond to effective surface temperatures of $290^{\circ} \mathrm{K}$ and $250^{\circ} \mathrm{K}$, respectively)

Using the values above we evaluated Equation (5) and (6) for uncertainties of $5 \%, 10 \%$ and $20 \%$ and Equation (7) for values of $A_{C L D}$ ranging from 0.3 to 0.7 .

\subsection{RESULTS AND DISCUSSION OF UNCERTAINTY ANALYSES}

Results of the uncertainty analysis for cloud amount $\left(A_{C L D}\right)$ shows that as the cloud amount varies, the relative uncertainty in cloud amount determination remains about 15 to $20 \%$. The absolute uncertainty thus remains in the 0.05 to 0.10 range for total cloud amounts less than 0.50 and when measurements and assumptions have $5 \%$ uncertainty. For example, with a11 uncertainty at the $5 \%$ level:

If:

\begin{tabular}{lll}
${ }_{C L D}$ & ${ }_{C L R}$ & Then $\Delta A_{C L D}$ \\
0.7 & 0.3 & 0.12 \\
\hline 0.5 & 0.5 & 0.09 \\
\hline 0.3 & 0.7 & 0.05 \\
\hline
\end{tabular}

Results of the uncertainty analysis for determining cloud top temperature 
showed that with measurement uncertainties of $5 \%$ and $A_{C L D}$ assumed to be \pm .05 then:

\begin{tabular}{|c|c|c|c|}
\hline${ }^{A} C L D$ & ${ }^{{ }^{A} C L R}$ & $\Delta T_{\text {eff }}$ & $\Delta \mathrm{Z}$ \\
\hline 0.7 & 0.3 & $5^{\circ} \mathrm{K}$ & $0.6 \mathrm{~km} *$ \\
\hline 0.5 & 0.5 & $10^{\circ} \mathrm{K}$ & $1.5 \mathrm{~km}$ \\
\hline 0.3 & 0.7 & $19^{\circ} \mathrm{K}$ & $3.0 \mathrm{~km}$ \\
\hline
\end{tabular}

As can be noted, we have the fortunate situation wherein the determination of cloud height is most difficult for scenes of low cloud amount but that the uncertainty in obtaining cloud amount is minimized for these scenes.

Overa11, the uncertainty analysis indicates that useful data from the bi-spectral technique is highly probable. Thus a simultaneous test of the method against ground observations was performed. (Simultaneously, satellite radiance measurements were tested for accuracy and stability (see Appendix 1).

\subsection{RESULTS FROM THE BI-SPEC PROGRAM}

In order to test the bi-spectral program, it was necessary to choose an area that corresponded to a location where cloud observations and upper air data were available. The first obvious location was WSMR since it took cloud observations during the time of the satellite pass and took frequent upper level soundings. Two other locations which were usually in good view by the satellite were chosen, Denver, Colorado and Oklahoma City, Oklahoma. We applied the bi-spectral model for a $2^{0} \times 2^{0}$

\footnotetext{
* to obtain this value it will be necessary to refine our measurements for $A_{C L D}$ since we found that $A_{C L D}$ could not be determined to \pm .05 for cloud amounts greater than ${ }^{0.5}$.
} 
latitude-longitude box centered on the location of interest. The problem arose of the size of an area to choose to correspond best with the ground observer's measurement of cloud amount. The method chosen was to assume a $40 \mathrm{mi}$. radial visibility in terms of sky cover measurements for the ground observer and to use data \pm 40 miles from the location of the site to compute an average cloud amount and cloud top temperature from the model output.

Figure 2 is a comparison of ground observed and satellite determined cloud amount and cloud height where standard meteorological symbols are used for amount for the WSMR area. Since these data correspond to the data set used for calibration, (See Table 1 in Appendix 1), it tends towards mostly clear cases. Thus, the bi-spectral technique handles this well as should be expected. In several cases shown here, the bispectral technique does pick out small scale fields of cumulus and towering cumulus building up over the white Sands region (Figure 3). For middle and higher type cloudiness the technique shows some discrepancies. Unfortunately, no estimate was made of the total opaque cloud amount in the surface observations made at White Sands as was done for Denver and Oklahoma City. Since our assumption of an emissivity of .9 is made of all emitting surfaces, we will obviously determine too warm a cloud-top temperature for surfaces less than this. In some instances when very thin cirrus is observed, the visible channel measurements are off as well since it views the underlying surface as well as the cloud. In some instances, as seen on November 13, 1974, we completely miss the clouds. This problem will appear in the two other locations and will be discussed in further detail in the next section. Table 2 gives the actual percentage amounts and heights of clouds observed as determined 


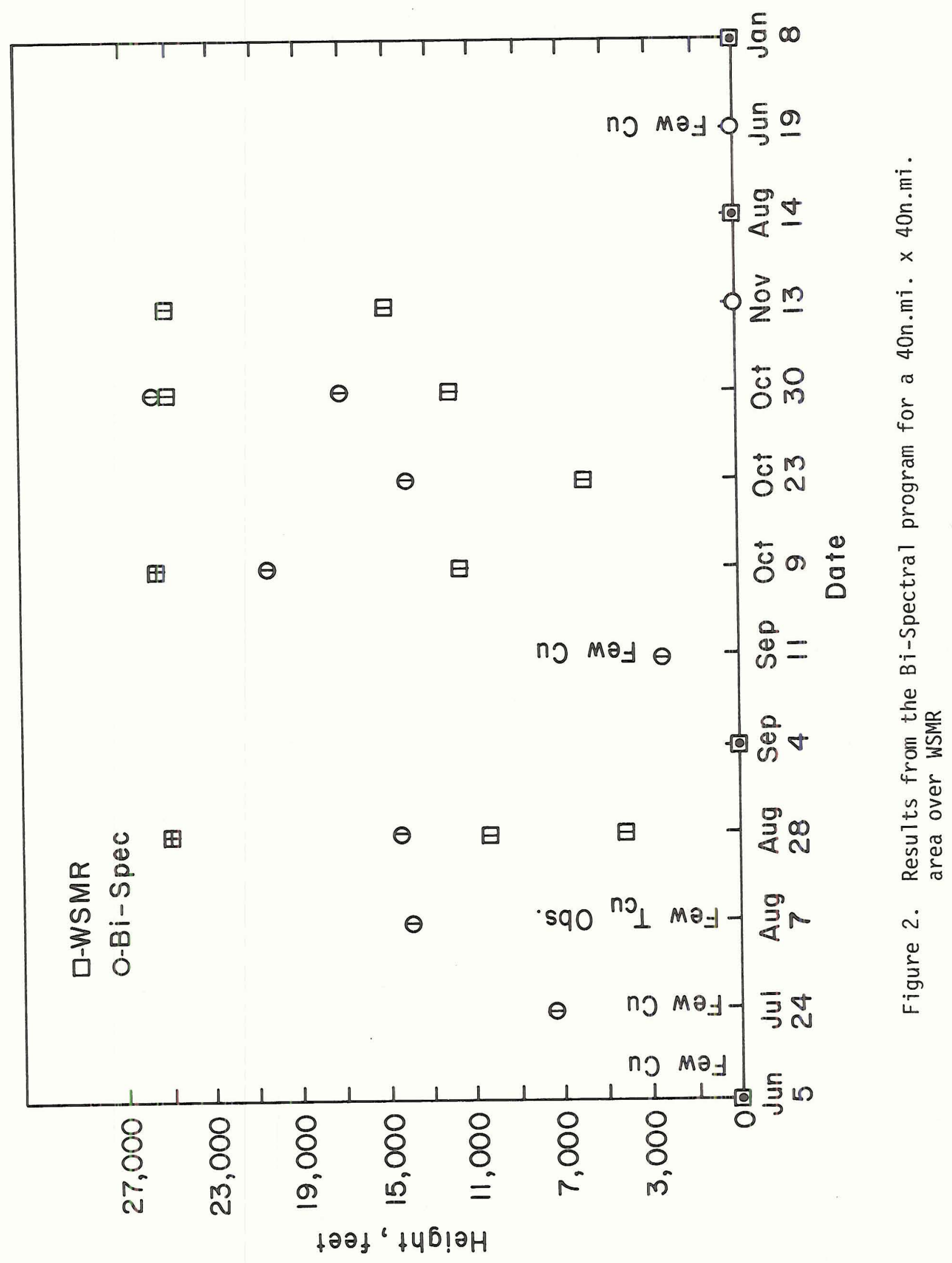



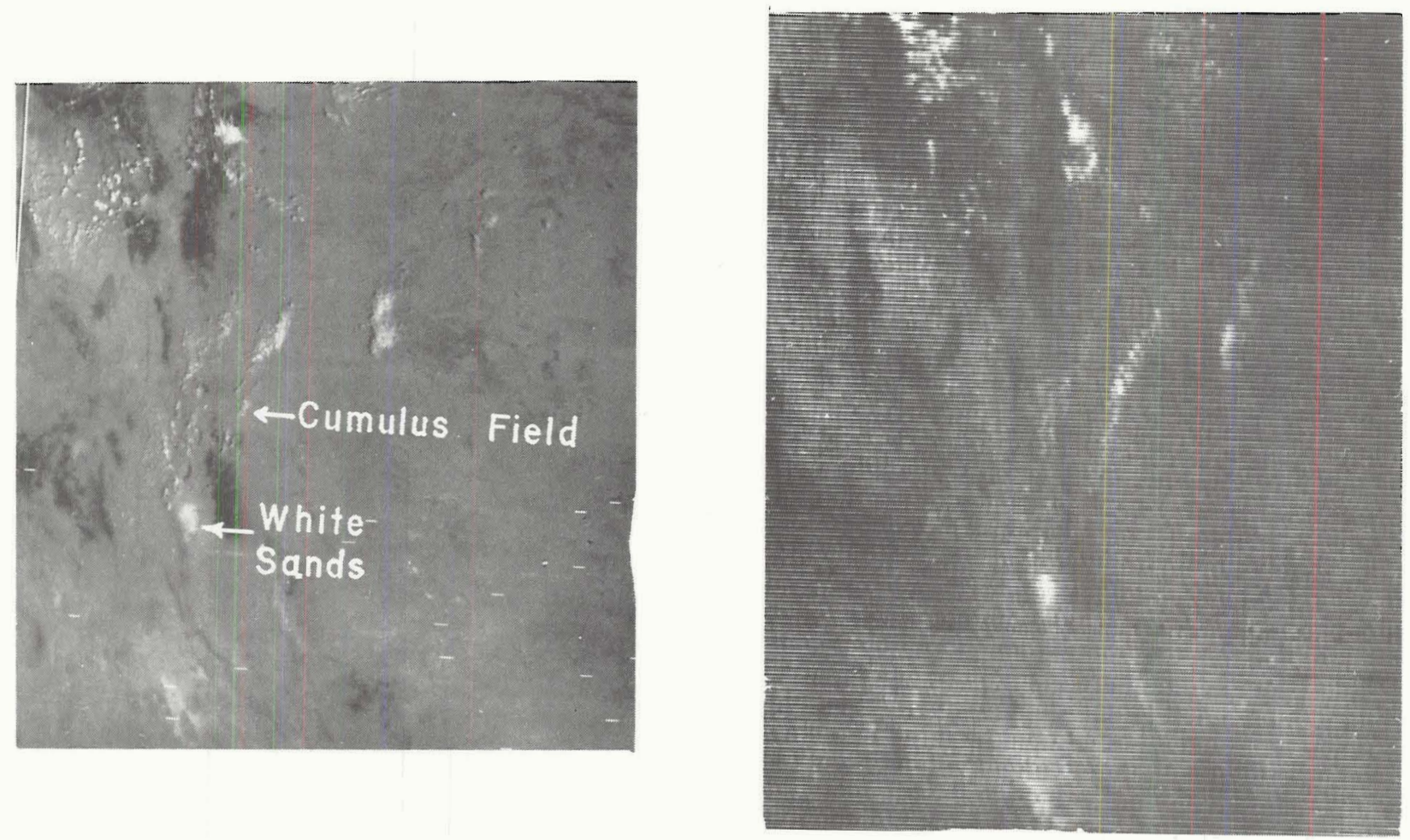

Figure 3. a.) NOAA-2 VHRR (Very High Resolution Radiometer) $1 \mathrm{Km}$ visible image for $9 / 11 / 74$ showing small cumulus just to the north of White Sands.

b.) NOAA-2 SR $4 \mathrm{~km}$ visible image for 9/11/74 corresponding to a.) above. 
WSMR MEASURED AND BI-SPEC HIGH RESOLUTION COMPARISON

\begin{tabular}{|c|c|c|c|c|}
\hline Date & Time & $\begin{array}{l}\text { High Res. } \\
\text { Calc. }\left({ }^{0}\right) \\
\end{array}$ & $\begin{array}{c}\text { WSMR } \\
\text { Meas. }\left({ }^{\mathrm{O}} \mathrm{K}\right) \\
\end{array}$ & Radian V Results \\
\hline $3 / 13 / 74$ & $1545 Z$ & 287 & 275 & \pm 0 \\
\hline $6 / 19 / 74$ & $1547 \mathrm{Z}$ & 308 & 310 & $-3^{\circ} \mathrm{C}$ \\
\hline $6 / 26 / 74$ & $1617 \mathrm{Z}$ & 310 & 308 & \pm 0 \\
\hline $8 / 14 / 74$ & $1718 \mathrm{Z}$ & 309 & 311 & -4 \\
\hline $10 / 9 / 74$ & $1657 Z$ & 288 & 312 & $\begin{array}{l}\text { Cloud Contamination } \\
250-3^{\circ} \mathrm{C}\end{array}$ \\
\hline $10 / 30 / 74$ & $1702 Z$ & 278 & 282 & $\pm 0^{\circ} \mathrm{C}$ \\
\hline $11 / 13 / 74$ & $1630 z$ & 275 & 280 & $250 \pm 0^{\circ} \mathrm{C}$ \\
\hline $1 / 8 / 75$ & $1650 Z$ & 275 & 275 & $\pm 0^{\circ} \mathrm{C}$ \\
\hline
\end{tabular}

WSMR MEASURED AND BI-SPEC CAİ. TEMP. COMPARISON

\begin{tabular}{|c|c|c|c|c|}
\hline Date & Time & $\begin{array}{l}\text { Bi-Spec } \\
\text { Calc. }(\mathrm{K}) \\
\end{array}$ & $\begin{array}{l}\text { WSMR } \\
\text { Meas. }\left({ }^{\circ} \mathrm{K}\right) \\
\end{array}$ & Radian V Results \\
\hline $6 / 5 / 74$ & $1647 Z$ & 319 & 323 & $\begin{array}{l}-1^{\circ} \mathrm{C} \text { Attenuation } .23^{\prime \prime} \\
\text { Precip. Water }\end{array}$ \\
\hline $7 / 24 / 74$ & $1708 \mathrm{Z}$ & 305 & 307 & $\begin{array}{l}-2^{\circ} \mathrm{C} \text { Attenuation } .54^{\prime \prime} \\
\text { Precip. Water }\end{array}$ \\
\hline $8 / 7 / 74$ & $1637 \mathrm{Z}$ & 298 & 302 & $\begin{array}{l}-4^{\circ} \mathrm{C} \text { due to Attenua- } \\
\text { tion . } 5^{\prime \prime} \text { Precip. } \\
\text { Water }\end{array}$ \\
\hline $8 / 28 / 74$ & $1.642 Z$ & 290 & 297 & $\begin{array}{l}\text { Possible Cloud } \\
\text { Contamination }-2.5^{\circ} \mathrm{C} \\
\text { Attenuation } .57^{\prime \prime} \\
\text { Precip. Water }\end{array}$ \\
\hline $9 / 4 / 74$ & 15332 & 294 & 298 & $\begin{array}{l}-2^{\circ} \mathrm{C} \text { Attenuation } .43^{\prime \prime} \\
\text { Precip. Water }\end{array}$ \\
\hline $9 / 11 / 74$ & 16072 & 293 & 301 & $\begin{array}{l}-2^{\circ} \mathrm{C} \text { Attenuation } .45^{\prime \prime} \\
\text { Precip. Water }\end{array}$ \\
\hline $10 / 23 / 74$ & $1624 Z$ & 288 & 288 & $\begin{array}{l}-2^{\circ} \mathrm{C} \text { due to Attenuation } \\
.4^{\prime \prime} \text { Precip. Water }\end{array}$ \\
\hline
\end{tabular}


TABLE 2

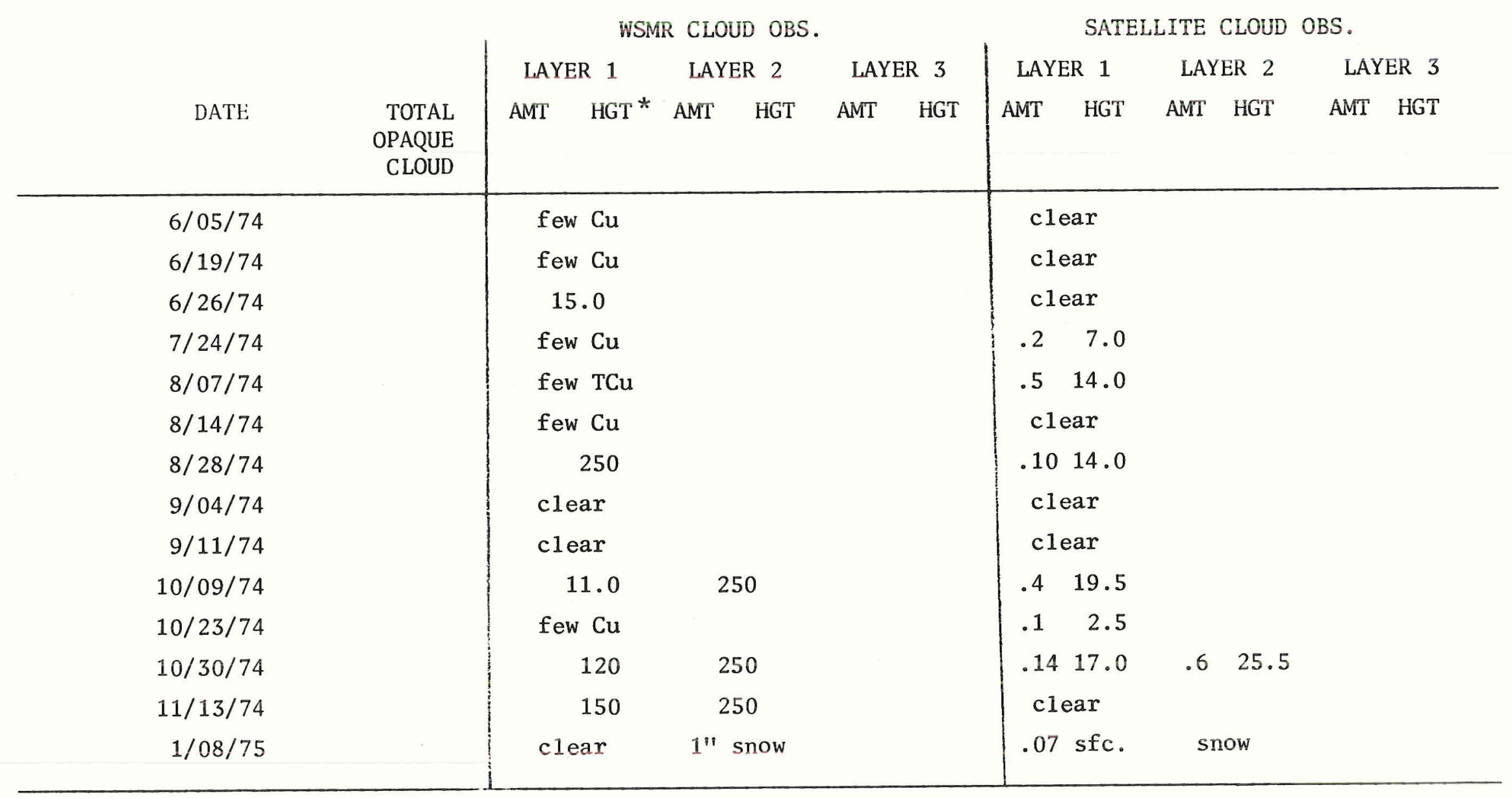

* in thousands of feet 
from satellites. In the Denver comparisons (Figure 4, Table 3), there were more cloudy cases, and the results seem quite good for all but the thin cirrus cases. On March 13, 1974, the technique was able to determine two layers of cloud which were observed, while on November 13, the satellite was able to determine the tops of the clouds while the observer reported sky obscured at $500 \mathrm{ft}$. Cases such as August 28 and October 23 point out the problem with cirrus and how the visible channel sees through them partially and underestimates amount while the IR determines too warm a temperature giving them too low a height. However the technique appears to do a good job at a fairly high resolution for the most part. You will note on this curve, the total opaque cloud amount as estimated by the observer is plotted. This number is more closely related to what the satellite sees than is the total cloud amount since the opaque cloud would have a higher optical depth and would have been seen by the satellite. Its emissivity would be closer to 1 allowing the proper temperature to be measured. The satellite is very close to both amount and height, in all but two instances, August 28 and October 23, when the opaque cloud amount is greater than .8. In the cases where the bi-spectral program measures a higher cloud height, it would obviously mean the satellite perceives the cloud-top while the observer sees cloud base. On the two cases mentioned above, the satellite determined close to the amount observed but measured too high a temperature. This shows that even with an apparent opaque cloud, the emissivity may not be 1 , thus allowing the satellite to measure too warn a temperature and consequently too low a height. There does not appear to be any correlation between errors in height and amount due to large satellite viewing angles. 


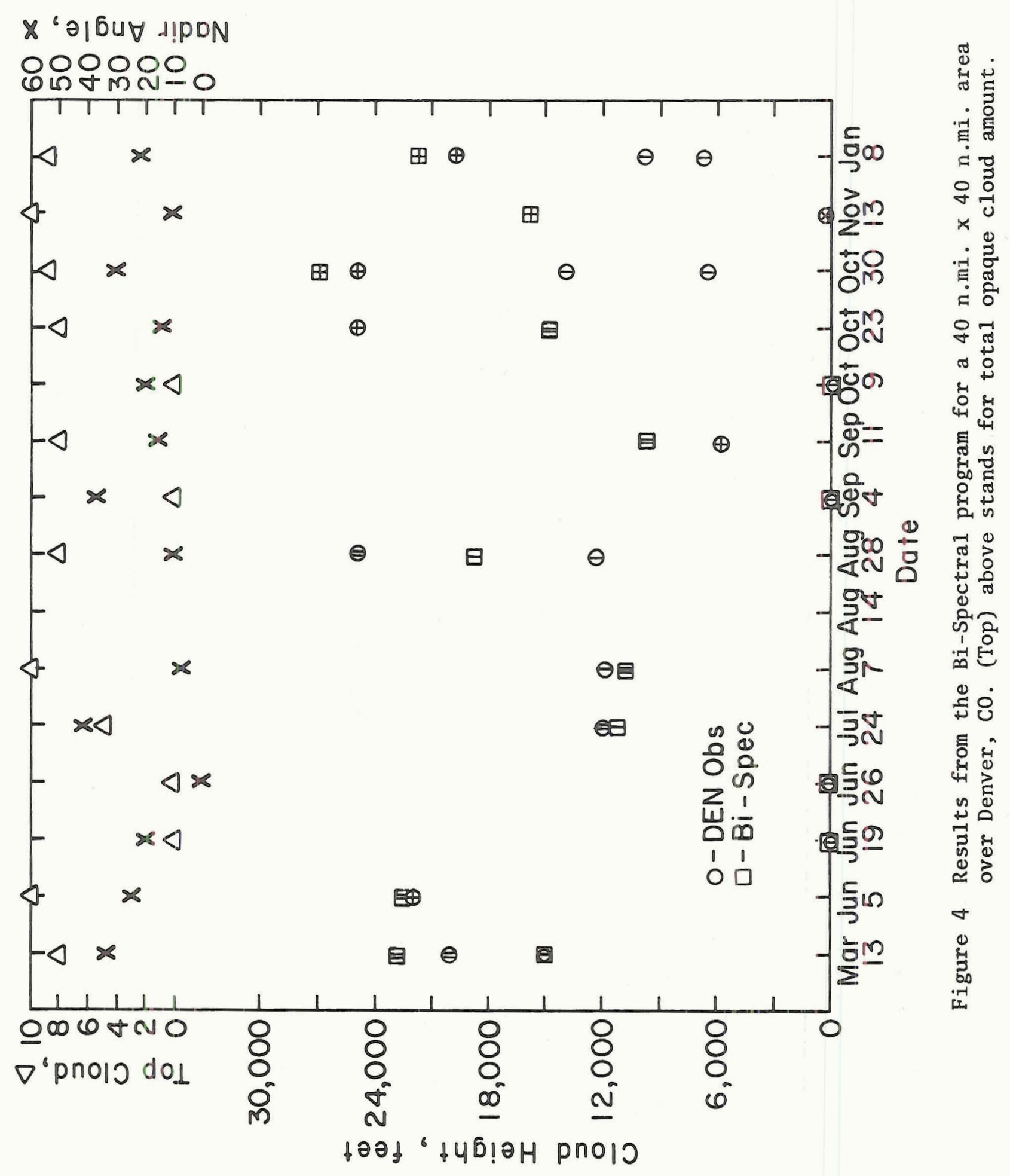


The third location chosen was OkTahoma City. As can be seen in Figure 5 and Table 4, there was a high percentage of thin cirrus and large viewing angles by the satellite. The thin cirrus problem is quite evident for the October 9 and November 13 cases. Here the observer reported $8 / 10$ cloudiness for both days but only $0 / 10$ and $1 / 10$ total opaque cloudiness, respectively. Therefore, on these days the satellite was not able to detect any cloudiness over OKC. In other instances, the satellite is able to determine multi-layered clouds when the observer was socked in by low clouds, such as $3 / 13$. On October 30 , the satellite seemed to be measuring the top of the thunderstorm over OKC while the observer could only see the base of the clouds. In most other cases where large errors occur, it is due to the assumption of a emissivity of .9, although the clouds observed definitely had an emissivity of less than this. Again, there doesn't seem to be any real error induced by low viewing angles, most of the error is due to the emissivity and optical depth problem.

\subsection{SPECIAL. APPROACH FOR THE CASE OF CIRRUS}

As has been shown by the previous results, cirrus clouds point out a special problem in the present technique for determining cloud amount and height. There are two approaches that can by used to try and determine the proper emissivity of these clouds. The first method is to correlate visible brightness to emissivity and correct the IR data by the emissivity determined by the visible channel. The second method is to use multispectral data available from the same NOAA satellite (VTPR Vertical Temperature Profile Radiometer data) and correlate the radiances of each spectral band to each other until a proper level is determined 
TABLE 4

\begin{tabular}{|c|c|c|c|c|c|c|c|c|c|c|c|c|c|c|}
\hline \multirow[b]{3}{*}{$\begin{array}{l}\text { NADIR } \\
\text { ANGLE }\end{array}$} & \multirow[b]{3}{*}{ DATE } & \multirow[b]{3}{*}{$\begin{array}{r}\text { TOTAL } \\
\text { OPAQUE } \\
\text { CLOUD }\end{array}$} & \multicolumn{6}{|c|}{ OKC CLOUD OBS. } & \multicolumn{6}{|c|}{ SATELLITE CLOUD OBS. } \\
\hline & & & \multicolumn{2}{|c|}{ LAYER 1} & \multicolumn{2}{|c|}{ LAYER 2} & \multicolumn{2}{|c|}{ LAYER 3} & \multicolumn{2}{|c|}{ LAYER 1} & \multicolumn{2}{|c|}{ LAYER 2} & \multicolumn{2}{|c|}{ LAYER 3} \\
\hline & & & AMT & HGT* & AMT & HGT* & AMT & HGT * & AMT & $\mathrm{HGT}^{*}$ & AMT & HGT* $^{*}$ & AMT & $\mathrm{HGT}^{*}$ \\
\hline $9^{\circ}$ & $3 / 13 / 74$ & 1.0 & 1.0 & 1.3 & & & & & .55 & 7.0 & .30 & 17.5 & .15 & 26.5 \\
\hline $45^{\circ}$ & $6 / 05 / 74$ & .6 & .1 & 3.0 & .7 & 250 & & & .5 & 9.4 & & & & \\
\hline $9^{\circ}$ & $6 / 19 / 74$ & 0 & & ear & & & & & $\mathrm{clc}$ & $a r$ & & & & \\
\hline $29^{\circ}$ & $6 / 26 / 74$ & 0 & & ear & & & & & & $\operatorname{ar}$ & & & & \\
\hline $48^{\circ}$ & $7 / 24 / 74$ & .1 & .4 & 30.0 & & & & & & 21.0 & & & & \\
\hline $35^{\circ}$ & $8 / 07 / 74$ & .2 & .2 & 5.0 & & & & & .1 & 7.0 & & & & \\
\hline $55^{\circ}$ & $8 / 14 / 74$ & .1 & .4 & 25.0 & & & & & .5 & 18.0 & & & & \\
\hline $36^{\circ}$ & $8 / 28 / 74$ & 1.0 & 1.0 & 1.3 & & & & & .75 & 21.4 & & & & \\
\hline $14^{\circ}$ & $9 / 11 / 74$ & & & ear & & & & & & ar & & & & \\
\hline $43^{\circ}$ & $10 / 09 / 74$ & 0 & .8 & 25.0 & & & & & & ar & & & & \\
\hline $32^{\circ}$ & $10 / 23 / 74$ & .5 & .5 & 8.0 & & & & & .4 & 7.3 & & & & \\
\hline $46^{\circ}$ & $10 / 30 / 74$ & 1.0 & 1.0 & 1.3 & $\mathrm{R}_{a} x$ & ported & & & 1.0 & 33.0 & & & & \\
\hline $13^{\circ}$ & $11 / 13 / 74$ & .1 & .8 & 25.0 & & & & & $\mathrm{cl}$ & $\operatorname{ar}$ & & & & \\
\hline
\end{tabular}

*in thousands of feet 
for the cloud.

To account for the cirrus problem equation (2) must be modified as follows:

$$
M_{L}=A_{C L R} N_{C L R}+(1.0-E) A_{C L D} N_{C L R}+E A_{C L D} N_{C L D}
$$

where:

$$
E=\text { emissivity }
$$

One method to obtain (E) would be to correlate the visible brightness of a cloud to its emissivity. This technique has been tried with varying success by Mosher (1974) and Shenk and Curran (1973). Measurements of cirrus clouds infrared emissivities (Kuhn and Weickman, 1969; Davis, 1971; Valovcin, 1968; Brown and Houghton, 1956; Platt, 1975; Hubert, 1975) and calculated by (Jacobowitz, 1970; Yamamoto et al., 1970; Fleming, 1973, and Liou, 1974) for varying geometric thicknesses have shown values ranging from .1 to .8 . In general the relation between (E) and the geometric thickness $(H)$ is poor, indicating that the ice crystal concentration ( $W$ in $g m . \mathrm{m}^{-3}$ ) has a major effect on the infrared emissivity.

It can be shown, (Fleming, 1973) that the reflected (scattered) solar radiance $\left(N_{r}\right)$ from a cirrus cloud is closely related to its effective optical depth $\tau^{*}=$ KWH where $K=$ an extinction coefficient dependent upon particle size and density. If we assume little absorption by the cirrus layer, then:

$$
a_{C L D}=1.0-e^{-\tau}{ }_{s}^{*} \sec \zeta
$$


where:

$$
\tau_{S}^{*}=\omega_{0} \tau *\left(\omega_{0}=\text { single scattering albedo } \approx 1.0\right)
$$

This relation between cirrus physical properties and cirrus albedo has a weak dependence on solar zenith angle $(\zeta$ ) for angles less than $60^{\circ}$.

From Liou (1974) it is possible to now relate $\tau *$ to infrared emissivity. From Figure 6 of Liou, if we assume a particle size of $40 \mu \mathrm{m}$ and use the curve for a number density of $\mathrm{N}=.02 \mathrm{~cm}^{-3}$ we obtain:

$\begin{array}{ll}\text { (wH) } & E \\ .0025 & 0.08 \\ .0049 & 0.15 \\ .0061 & 0.17 \\ .0099 & 0.27 \\ .0123 & 0.34 \\ .0148 & 0.39 \\ .0197 & 0.50 \\ .0246 & 0.60 \\ .0369 & 0.75 \\ .0492 & 0.90 \\ .0615 & 0.95\end{array}$

Then using Equation (8) we can relate albedo to $\mathrm{E}$ (see Figure 6 ). Using this graph and the albedo measured by the satellite over cirrus it would be possible to obtain an estimate of the emissivity of the cloud to use in Equation $\left(2^{\prime}\right)$. Two cases were studied to test the relationship between albedo and temperature as measured by the satellite. One case (Figure 7) was of cirrus over the Gulf of California; the other of cirrus over the southern part of Arizona (Figure 8). Both show a fairly strong relationship between $T_{\text {eff }}$ and ${ }^{{ }_{C}}{ }_{L D}$, even though the cirrus over land shows a shift to higher albedoes due to the contribution of the albedo of the

${ }^{1}$ note that $w=.231 \mathrm{~N}$ for cirrus crystals of radii equal to $40 \mu \mathrm{m}$ where the number density is in $\mathrm{cm}^{-3}$ (see Fleming, 1973). 


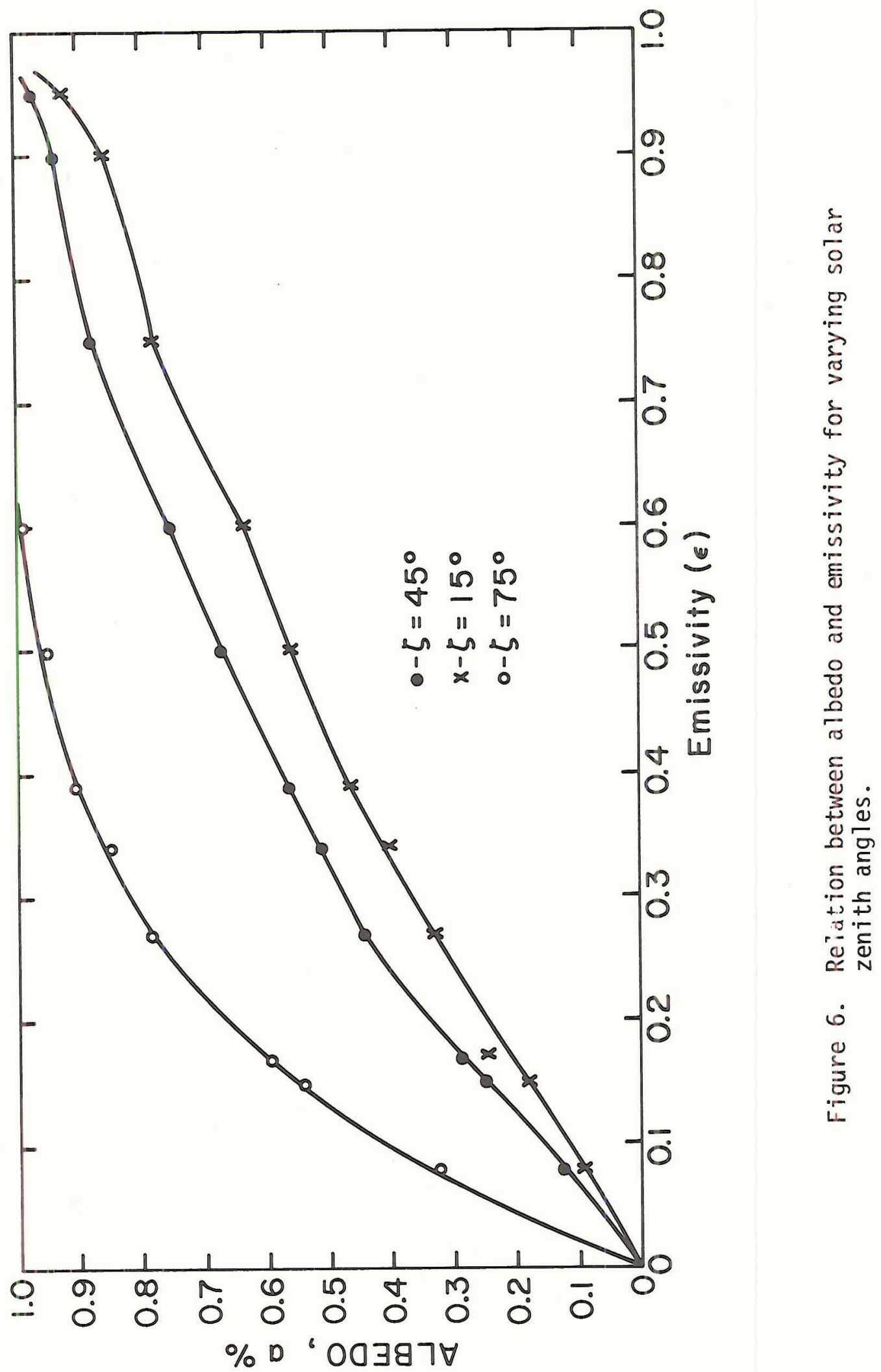




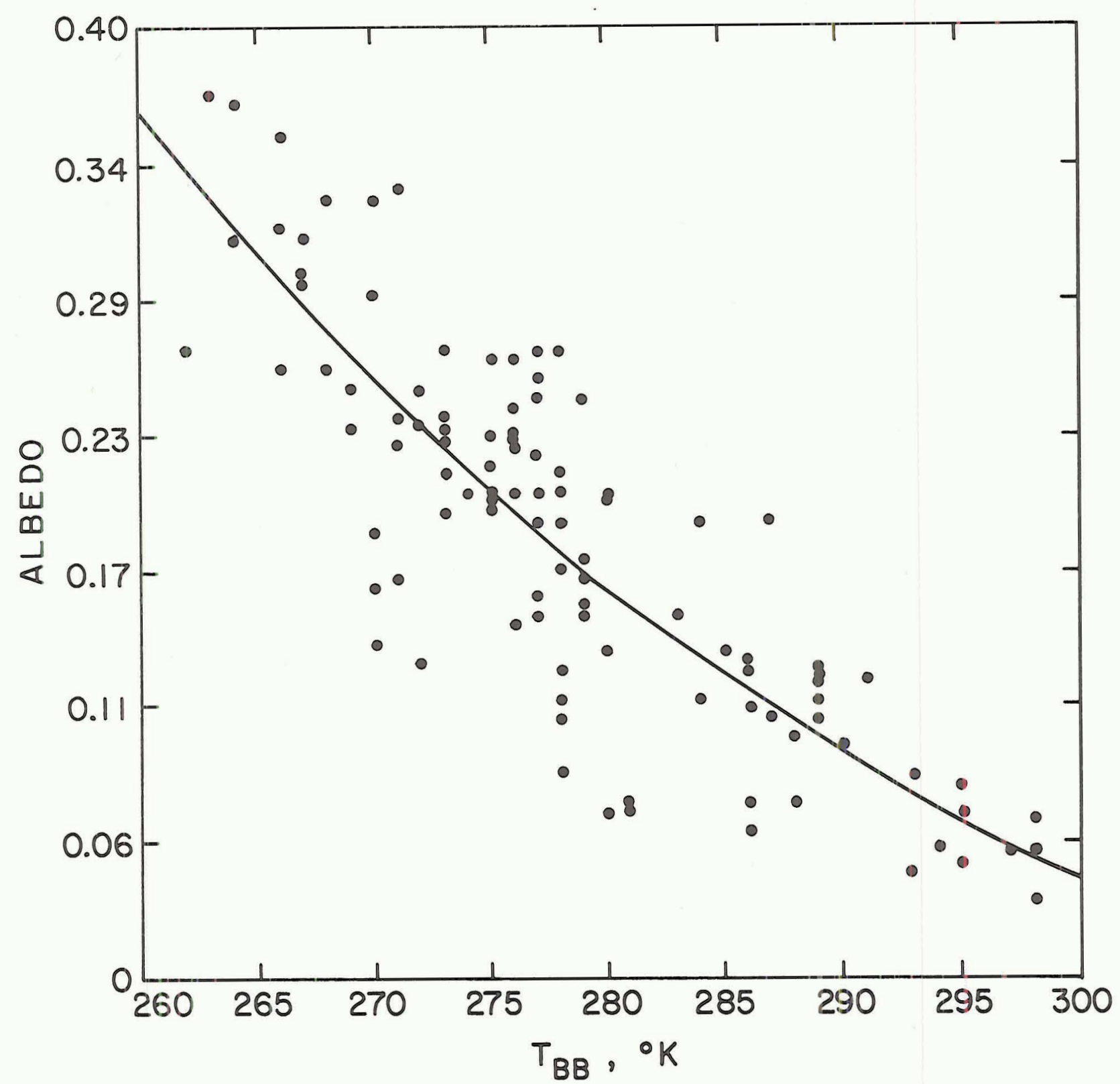

Figure 7. Relationship between albedo and blackbody temperature as derived from NOAA SR measurements of cirrus over the Gulf of California. 


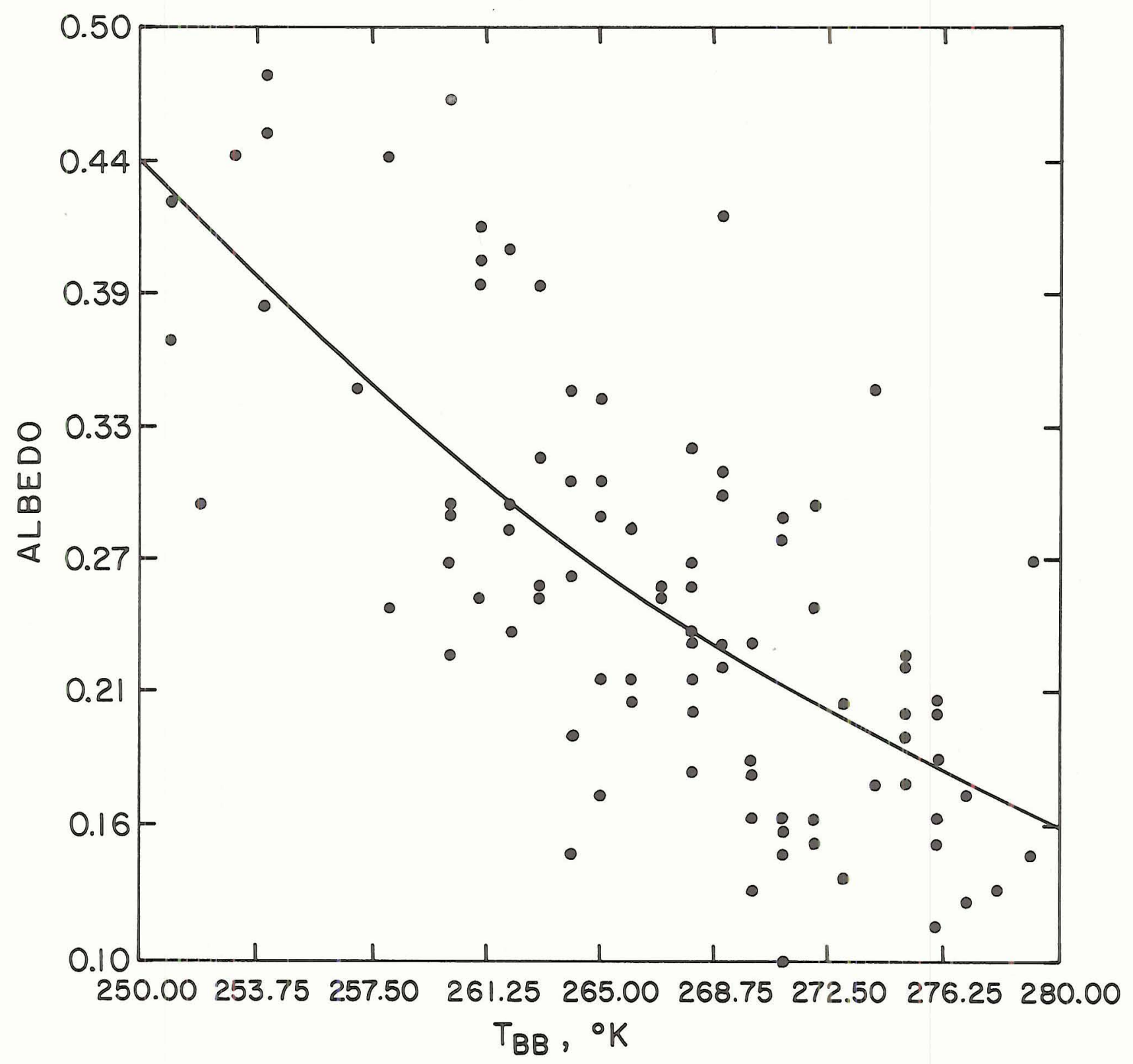

Figure 8. Relationship between albedo and blackbody temperature as derived from NOAA SR measurements of cirrus over southern Arizona. 
land surface through the cloud. This does point out that two sets of relationships must be developed to account for the differences of landocean reflectance. Shenk and Curran (1973) have tested this technique for satellite measurements of cirrus over the North Atlantic Ocean. After their Figure 3 (Figure 9) they developed a set of curves by using Equation 2' assuming total cloud cover in the field of view of the sensor. They then developed a family of curves for different cloud tops using $288^{\circ} \mathrm{K}$ as $N_{C L R}$ and using measured IR values $T_{B B}\left(M_{L}\right)$. For their measurements they found that for a cloud of $a=25 \%, T_{B B}=265^{\circ} \mathrm{K}$, that the $E$ would equal .5. Using the work of Liou for $a=25 \%$ and $\zeta=15^{\circ}$, an $E=.3$ would be determined. Thus it appears as though a relationship should be developed for a specific satellite experiment. This should be in relation to special cloud and ground truth measurements during the observation time of the satellite.

A second method that could be used, and will be tested, has been developed by Bunting and Conover (1974) using multi-spectral radiance data from the VTPR experiment onboard the NOAA satellites.* This system uses a radiative transfer model which tries to simulate the radiance that should be seen by the satellite viewing a given cloud at a certain height and emissivity. Model clouds were then found which satisfied four of the spectral regions (bands $4,5,6,8$ ), each characterized by an emissivity and a cloud-top height. Shown in Figure 10 is their Figure 1, a comparison of their channel 4 and 8 where the overlap denotes the location of the assumed cloud height and the clouds emissivity.

*0ther techniques using vertical temperature sounding data have been developed by Chahine (1974) and Smith (1975) to determine fractional cloud amount and height and both show promise for determining large scale cloudiness. 


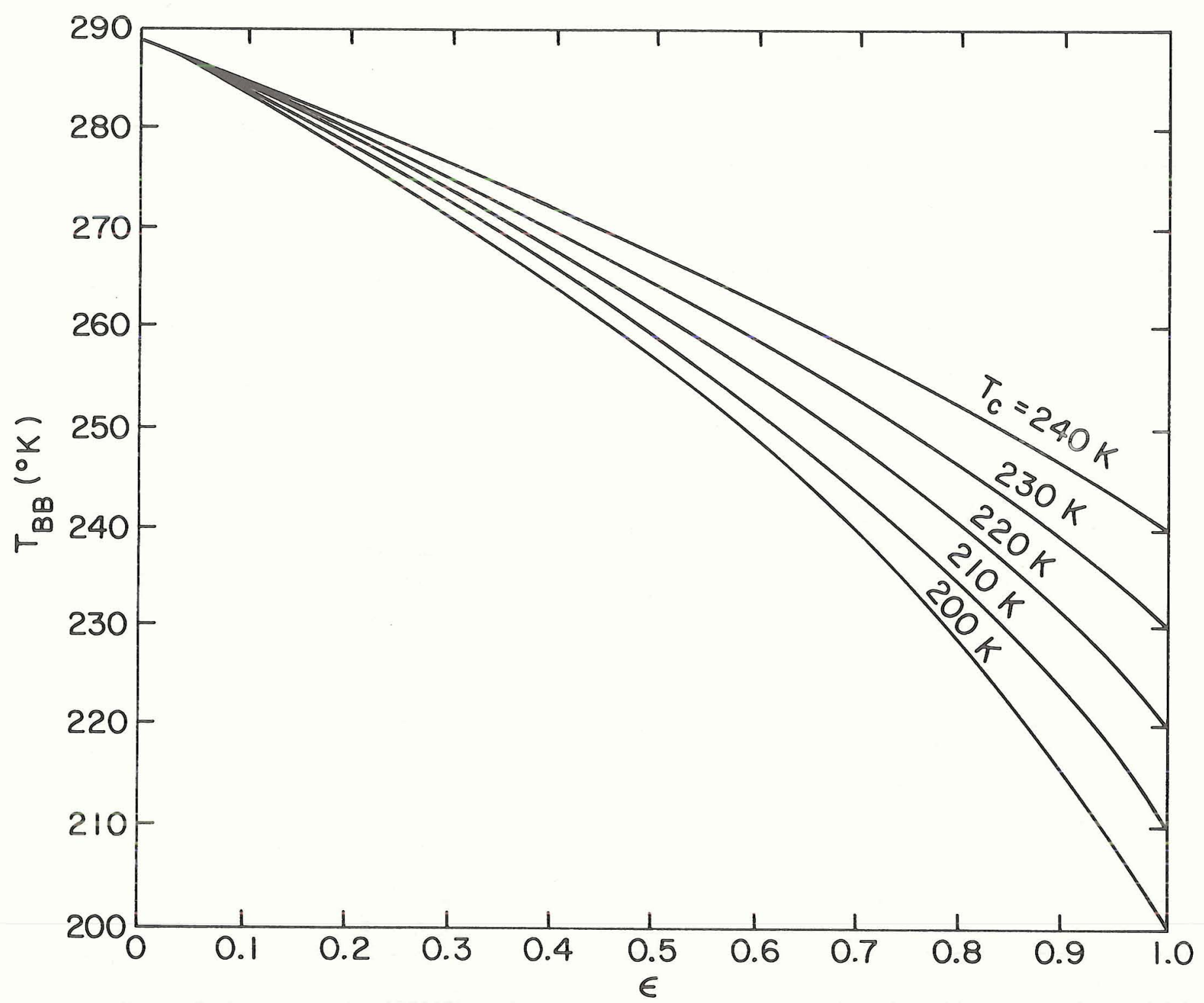

Figure 9. Family of curves relating true cloud top temperature (TC) to what would be measured by satellite for given emissivities (From Shank and Buran, 1973). 
Aircraft comparisons during the time of the NOAA pass show this scheme to work quite well. With the use of the SR data in conjunction with this data, it may be possible to fine-tune the VTPR calculation through use of the higher resolution SR data. Thus, this technique would become a multi-spectral rather than a bi-spectral technique to determine cloud heights and amounts.

A third approach to overcome the cirrus problem is to use a $6.7 \mu \mathrm{m}$ channel to discriminate between cirrus and clear conditions in the upper troposphere (Shenk et a1., 1974). However, this method is open to some difficulty of interpretation when upper tropospheric water vapor content changes.

\subsection{SUMMARY AND CONCLUSIONS}

This paper has presented a technique to determine cloud amount and cloud height using simultaneous visible and infrared data obtained from the NOAA satellite. Several assumptions are necessary in the development of this technique, but the uncertianty analysis has shown that with proper ground-truth calibration, reasonable and useful results can be expected. Cursory ground-truth comparisons have shown that the IR channel appears to give reasonable results while comparisons with the visible channel appears to contain factors that have not been accounted for to date. Due to these factors and the lack of cloud-truth data at a resolution of the NOAA satellite, we have not been able to test the accuracy of the technique for individual scan spots. When an árray of satellite data is taken, comparisons to ground observed cloud amounts show good comparison for all but the cirrus cases. Two techniques were described which could correct this problem and will be tested and incorporated into this technique 
to allow measurements of all cloud types. This method has many applications and can be used by many of the present satellites now in orbit. The VISSIR (Visible and Infrared Spin Scan Radiometer) data available from the GOES series of satellites is probably the best available for use with this method. The DMSP (Defense Meteorological Satellite Program) satellites also have dual-channel radiometers capable of using this technique on an operational basis. It appears now as though many of the future satellites such as the TIROS-N series will have this dualchannel capability and will be potential candidates for use in determining cloud information using the bi-spectral method. 


\section{ACKNOWLEDGEMENTS}

This research was supported by the Global Atmospheric Research Program, NSF, and the GATE Project Office, National Oceanic and Atmospheric Administration. Support was also provided by the Meteorological Technical Area of the U.S. Army Electronics Command, White Sands Missile Range, New Mexico. 
Appendix 1: Test of Accuracy and Reproducibility of Satellite Radiative Measurements

To check the accuracy of the satellite measurements, inflight calibration of the visible and infrared sensor is needed. One method is to have the sensor scan a surface target of known brightness and temperature and compare this to the digitized visible and IR data received from the SR sensor of the NOAA satellites*. One such target is the White Sands National Monument where the Atmospheric Sciences Laboratory at White Sands Missile Range has set up a ground truth site (Williamson, 1975). At this site measurements are made of the surface radiation temperature in the $10-11 \mu \mathrm{m}$ range with a Barnes PRT-5, as well as the incoming and outgoing radiant flux in the $.5-.7 \mu \mathrm{m}$ range using an Eppley Model 2 Precision Spectral Pyranometer. Measurements are simultaneous with the passage of the NOAA satellite allowing nearly direct comparisons once viewing angle, sun angle, and water vapor attenuation problems are taken into account.

Some preliminary comparisons are shown in Figs. 11 and 13. Fig. 11 is a comparison of ground based measured radiative surface temperature and satellite measured surface temperature. Both raw data and data corrected for limb darkening and water vapor absorption are shown in the figure. An IR radiative transfer model having 10 wavenumber resolution incorporating Bignel1's pressure broadened continuum developed by Cox (1975) was used for this calculation. Table 1 shows the loss that was calculated due to water vapor absorption (note preceipitable water) and 1 imb darkening. As the graph shows in Fig. 12, almost all points are below the 1:1 1ine showing the satellite was measuring a colder temperature then was measured at the surface.

*Data is received by use of the CSU APT station then is digitized at full resolution for use in the $B i-S p e c$ program. 


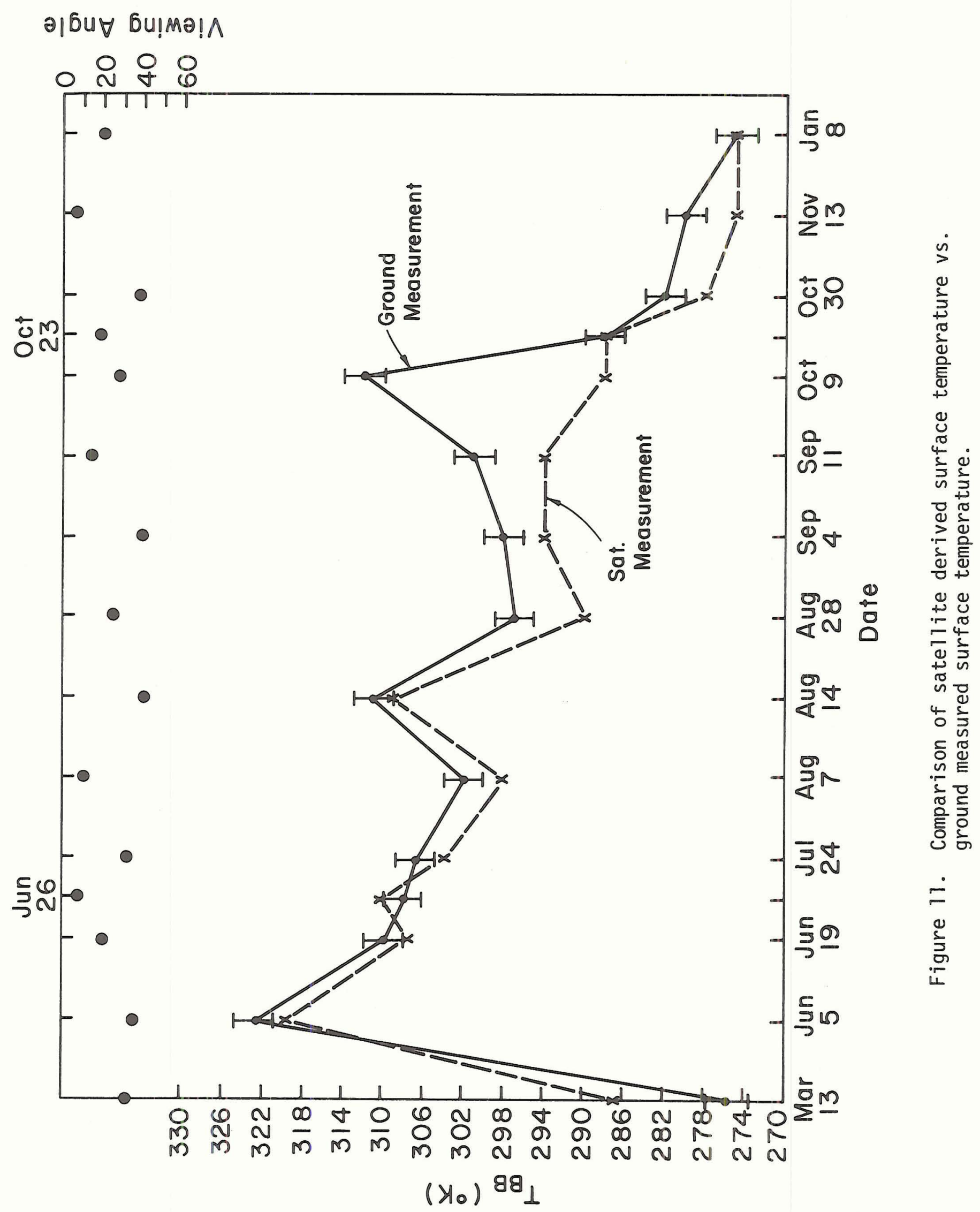




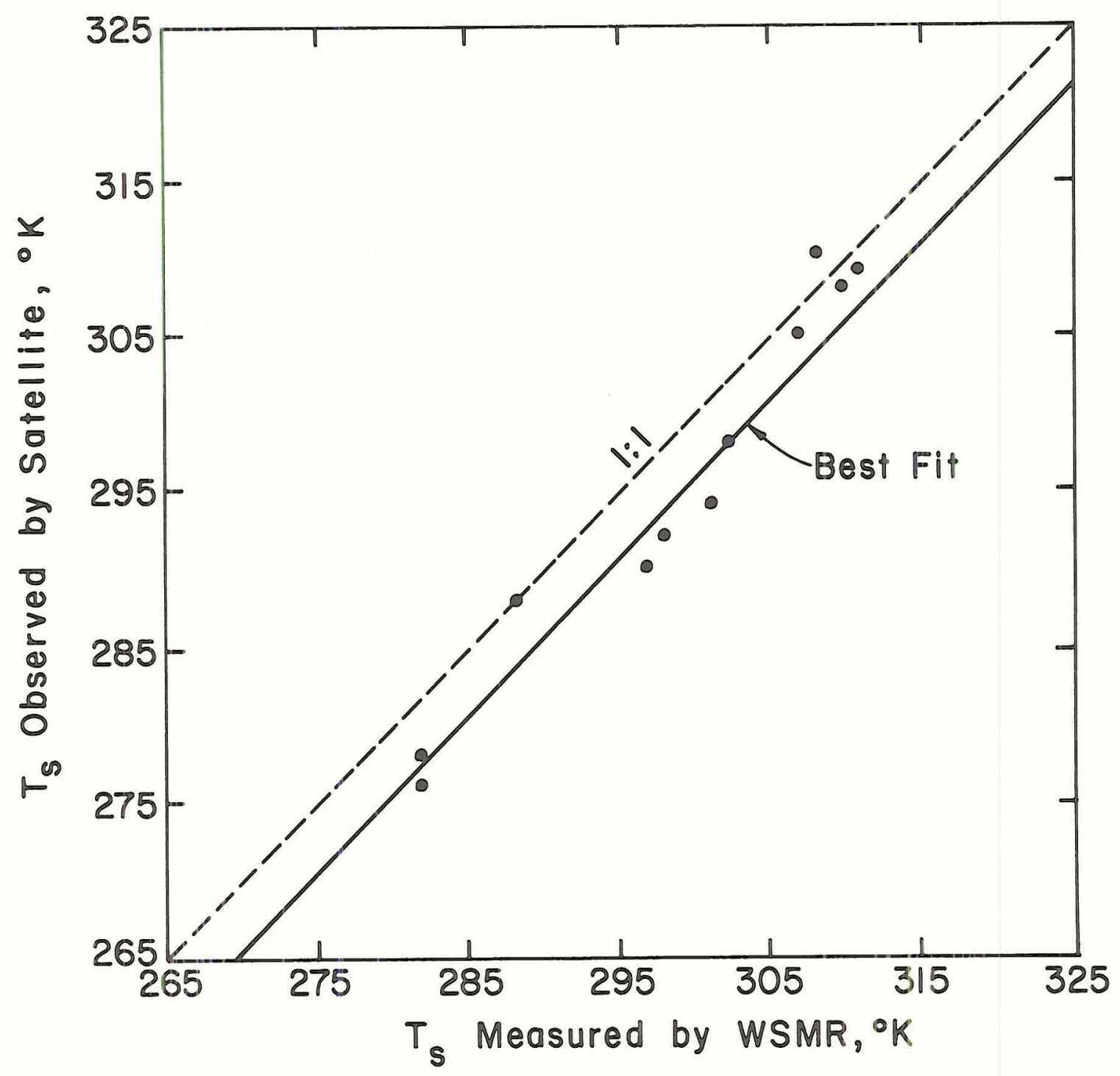

Figure 12. Best fit curve of observed satellite surface temperature and ground measured surface temperature showing the satellite measures a temperature approximately $3^{\circ} \mathrm{C}$ colder on the average. 
Possible causes for this discrepancy are due in part to: 1) Theoretical model not accounting for all the absorption taking place between the surface and satellite (i.e., haze problems, etc.); 2) To arrive at a surface temperature for White Sands from the satellite it was necessary to average the IR data over the visually brightest area which could be as large as $40 \mathrm{sq} . \mathrm{km}$. This averaging technique takes into account a much larger area than the field of view of the PRT (a few meters) which may cause a discrepancy in the two measurements; 3) Calibration errors are another source of error; and 4) Difference in radiometers, i.e., spectral response and sensitivity differences between the satellite sensor and ground sensor. The best fit curve shows what could be assumed to be the best relationship between the ground and satellite measurements. It still shows quite a bit of scatter around the curve but probably accounts for some of the systematic errors. More measurements are definitely needed and are continuing on a weekly basis through cooperation of CSU and WSMR.

For the visible channel, comparison was made of the albedo as measured from the surface, to that which was measured by the satelite (fig. It was necessary to correct the satellite data for viewing angle, sun angle, and bi-directional reflectance problems (Sikula and Vonder Haar, 1972). The results show that in only a few instances do the measurements attain the $5 \%$ accuracy we feel is needed. Work done by Walraven and Coulson (1972) have shown there is definitely a bi-directional reflectance problem with the White Sands which will affect the measurements. Our bi-directional reflectance model is based on clouds which does not exactly represent the reflectance of the sand and will cause discrepancies in the two measurements. Cox (1975) has shown that over a bright surface the atmosphere would absorb reflected radiation causing a lower albedo to be measured from the satellite. Many of the factors affecting the IR channels, 


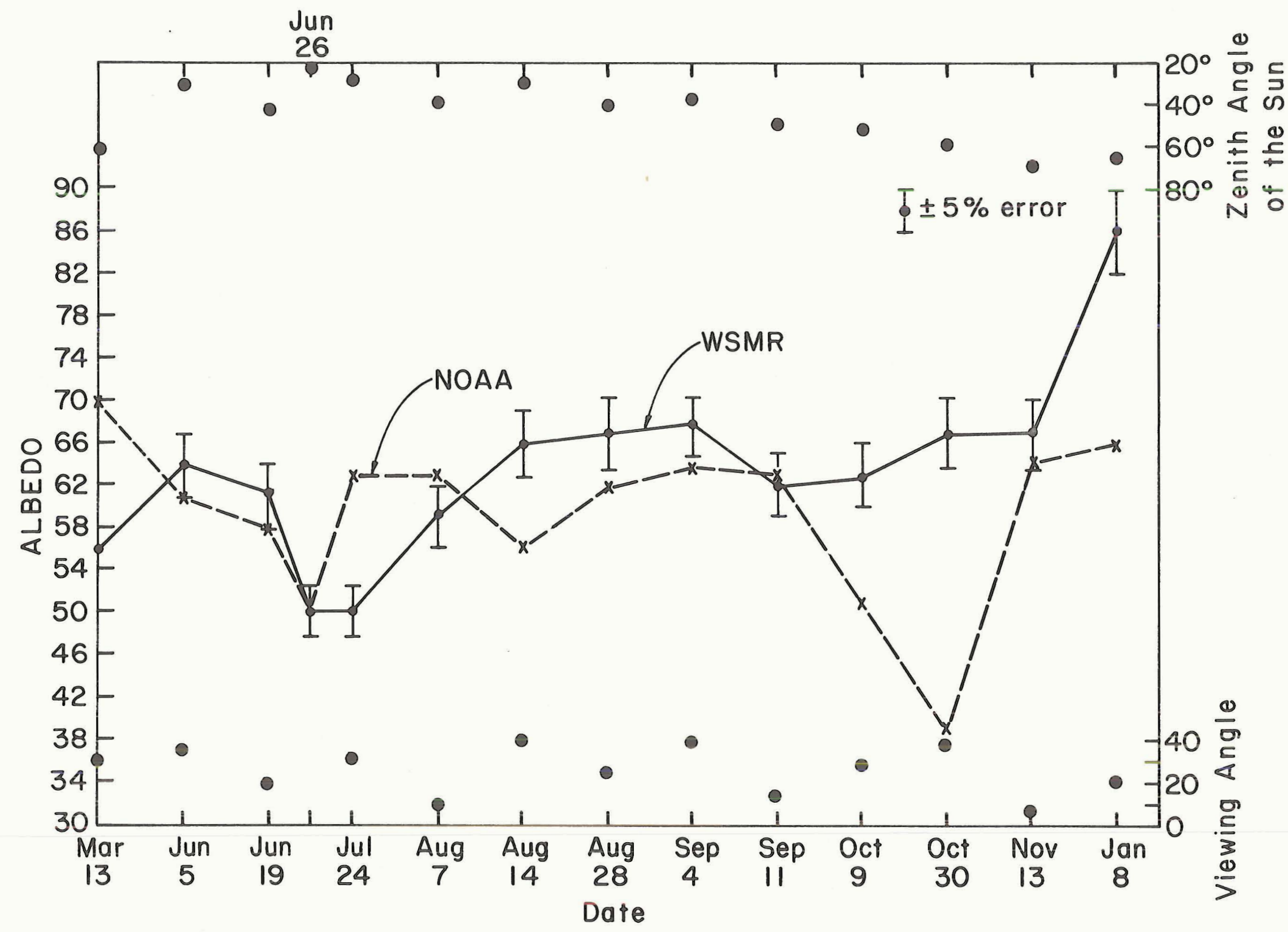

Figure 13. Comparison of satellite measured surface albedo to ground based measured surface albedo for White Sands. 
such as calibration, instrument/spectral differences, and size of area measured, affect the final reading. These several factors affecting the reflectance measurements have to be accounted for. (See Jacobowitz and Gruber, 1975, for a discussion of these).

The uncertainty analysis has shown that at a $5 \%$ level of uncertainty in the measured values we can assume reasonable values in cloud amount and cloud top temperature. However, comparisons to "ground truth" data show we may not have this accuracy in the IR or visible channel. This can be accounted for since the error in the IR seems to be a systematic decrease as measured by the satellite. The visible channel presents a somewhat more complicated problem and requires further study. Thus, sidestepping this problem for the moment, we have proceeded to run test cases to ascertain the accuracy of this technique in Section 5. There we will avoid using individual "spots" for verification but will use an average array. This will somewhat eliminate some of the errors by smoothing the data. 


\section{BIBL IOGRAPHY}

Booth, A.L., 1973: Objective cloud type classification using visual and infrared satellite data. Tech Note BN-768, Institute for Fluid Dynamics and Appl. Math., U. of Maryland, College Park, 62 pp.

Brewer, A.W. and J.T. Houghton, 1956: Some measurements of the flux of infrared radiation in the atmosphere. Proc. Roy. Soc. (London), 20, $167-175$.

Bunting, J.T. and J.H. Conover, 1972: Progress on derivation of cloud water content from satel1ites. Preprint from lst Conf. on Atmos. Rad. of the AMS. Aug. 7-9, Colorado State U., Fort Collins.

Chahine, M.T., 1974: Remote sounding of cloudy atmospheres, I. The single cloud layer. J.Atmos. Sci., 37, 1, pp. 233-243.

Conover, J.H., 1963: Cloud interpretation from satellite altitudes. AFCRL-62-680, Supplement 1, Air Force Cambridge Research Lab., L. G. Hanscom Field, Bedford, MA, $19 \mathrm{pp}$.

Cox, S.K., 1975: Relating broadband shortwave irradiance measurements to radiative properties of the atmosphere. Presented at 2 nd Conf. on Atmos. Rad., Oct. 29-37, Arlington, VA

Davis, P.A., 1970: Airborne ruby-1idar and radiometric measurements of cirrus and haze during BOMEX. Project 7334, Stanford Research Institute, $\mathrm{CA}, 97 \mathrm{pp}$.

Fleming, J.R., 1973: Radiative effects of cirrus clouds. Atmos. Sci. Tech. Rep. 207, Dept. of Atmos. Sci., Fort Collins, CO.

Hubert, L.F., 1975: Note on jet stream cirrus emissivity. Quart. J. R. Met. Soc., 101, pp. 1017-1019.

Jacobowitz, H., 1970: Emission, scattering and absorption of radiation in cirrus cloud layers. Ph.D. dissertation, MIT, 181 pp.

Jacobowitz, H. and A. Gruber, 1975: Calibration of the visible channel of the NOAA-2 radiometer. Presented at Second Conference on Atmos. Rad. of the AMS, Oct. 29-31, Arlington, VA

Kuhn, P.M. and H.K. Weickmann, 1969: High altitude radiometric measurements of cirrus. J. Appl. Meteor., 8, 1, 147-154.

Leese, J.A., 1964: Quantitative interpretation of low-level cumuliform cloud patterns as seen in meteorological satellite videographs.

Final Report, Contract Cwb-10795, U. of Michigan, Ann Arbor, Mich., $205 \mathrm{pp}$.

Liou, K., 1974: On the radiative properties of cirrus in the window region and their influence on remote sensing of the atmosphere. J. Atmos. Sci., 31, 522-532. 
Miller, D.B., R.E. Miller and A.L. Booth, 1970: An automated method of estimating total cloud amount from mesoscale satellite data. Proceedings of the Symposium on Tropical Met., June 2-, Honolulu.

Mosher, F.R., 1974: SMS cloud heights. Space Science and Engineering Center., U. of Wisconsin, Madison.

Platt, L.M.R., 1975: Infrared emissivity of cirrus-simultaneous satellite Tidar and radiometric observations. Quart. J.R. Met. Soc., 101, pp. 119-126.

Shenk, W.F. and R.J. Holub, 1972: A multispectral cloud type indentification method using Nimbus 3 MRIR measurements. Preprint Conf. on Atmos. Rad., AMS, Colorado State Univ., Fort Collins.

Shenk, W.E. and R.J. Curran, 1973: A multi-spectral method for estimating cirrus cloud top heights. J. Appl. Meteor., 12, 8, 1213-1216.

Shenk, W.E., R.J. Holub, R,A. Neft, 1974: A multi-spectral cloud type identification method developed for tropical ocean areas with Nimbus-3 MRIR measurements. Unpublished manuscript.

Sikula, G.J. and T.H. Vonder Haar, 1972: Very short-range local area weather forecasting using measurements from geosynchronous meteorological satellites, AFCRL-72-0260.

Smith, W.L., H.M. Woolf, P.G. Abel, C.M. Hayden, M. Chalfant, N. Grody, 1974: Nimbus 5 sounder data processing system. Part I: Measurement characteristics and data reduction procedures. NOAA Tech Memo NESS 57. 99 pp.

Smith, W.L., 1975: The Nimbus-6 sounding experiment, A prototype of the satellite sounding system during the FGGE. Presented at "The JOC Study Group Conference on Four Dimensional Data Assimilation", Paris, France, 17-21 November.

Valovcin, F.R., 1968: Infrared measurements of jet stream cirrus. J. Appl. Meteor., 7, 817-826.

Vonder Haar, T.H., 1970: Application of simultaneous infrared radiation measurements and cloud photographs from satellites. J.Appl. Meteor., 9, 6, 955-958.

Vonder Haar, T.H., E. Raschke, W. Bandeen, M. Pasternak, 1973: Measurements of solar energy reflected by the earth and atmosphere from meteorological satelitites. Solar Energy, 14, pp. 175-184

Wa1raven, R.L. and K.L. Coulson, 1972: Measurements of the 1ight reflecting properties of white gypsum sand. Contribution in Atmospheric Science, no. 7, U. of California, Davis. 